\title{
The Relationship between Urban Sprawl and Coronary Heart Disease in Women
}

\author{
Beth Ann Griffin a, ${ }^{*}$, Christine Eibnera, Chloe E. Bird ${ }^{b}$, Adria Jewell $^{a}$, Karen Margolis ${ }^{c}$, \\ Regina Shih ${ }^{\mathrm{a}}$, Mary Ellen Slaughter ${ }^{\mathrm{d}}$, Eric A. Whitse ${ }^{\mathrm{e}}$, Matthew Allison ${ }^{\dagger}$, and Jose J. \\ Escarce $^{g}$ \\ aRAND Corporation, 1200 South Hayes Street, Arlington, VA 22201 \\ bRAND Corporation, 1776 Main Street, Santa Monica, CA 90401 \\ cHealthPartners, Bloomington, MN \\ ${ }^{d}$ RAND Corporation, 4570 Fifth Avenue, Suite 600, Pittsburgh, PA 1521 \\ eUniversity of North Carolina, Chapel Hill \\ fUniversity of California, San Diego \\ gUniversity of California, Los Angeles
}

\begin{abstract}
Studies have reported relationships between urban sprawl, physical activity, and obesity, but- to date-no studies have considered the relationship between sprawl and coronary heart disease (CHD) endpoints. In this analysis, we use longitudinal data on post-menopausal women from the Women's Health Initiative (WHI) Clinical Trial to analyze the relationship between metropolitan statistical area (MSA)-level urban compactness (the opposite of sprawl) and CHD endpoints including death, any CHD event, and myocardial infarction. Models control for individual and neighborhood sociodemographic characteristics. Women who lived in more compact communities at baseline had a lower probability of experiencing a CHD event and CHD death or MI during the study follow-up period. One component of compactness, high residential density, had a particularly noteworthy effect on outcomes. Finally, exploratory analyses showed evidence that the effects of compactness were moderated by race and region.
\end{abstract}

\section{Keywords}

Urban Sprawl; Coronary Heart Disease; Neighborhoods; Women's Health

\section{Introduction}

Urban sprawl, an aspect of the built environment characterized by low population density, automobile dependence, and single-use land zoning, has been identified as a public health hazard for many reasons. A substantial body of work has linked sprawl to increased body mass index (BMI) (Lopez, 2004; Vandergrift and Yoked, 2004; Ewing et al., 2006; Ross et

\footnotetext{
(C) 2012 Elsevier Ltd. All rights reserved.

*Corresponding author phone (703) 413-1100 ext. 5181, bethg@ rand.org.
}

Publisher's Disclaimer: This is a PDF file of an unedited manuscript that has been accepted for publication. As a service to our customers we are providing this early version of the manuscript. The manuscript will undergo copyediting, typesetting, and review of the resulting proof before it is published in its final citable form. Please note that during the production process errors may be discovered which could affect the content, and all legal disclaimers that apply to the journal pertain. 
al., 2007; Rundle et al., 2007) and reduced physical activity (Ewing, Pendall, and Chen, 2003; Saelens et al.; 2003; Suminski et al., 2005), possibly due to its negative impact on active transport such as walking - either as a mode of transportation or as a form of exercise. Moreover, studies have found associations between attributes of neighborhood design that are related to sprawl, such as aesthetics, presence of sidewalks, and street connectivity, and physical activity (Saelens and Handy, 2008) and body mass index (BMI; Papas et al., 2007).

Sprawl could lead to adverse health outcomes both through the direct effects of obesity and lack of exercise, as well as through other pathways. For example, urban sprawl may reduce community-level social capital by increasing commute times and creating geographic barriers between areas where people work, live, and shop (Putnam, 2000; Besser et al., 2008). Low social capital, in turn, is an independent risk factor for poor self-rated health (Kawachi et al., 1999; Kim et al., 2006; Fujiwara and Kawachi, 2008), coronary heart disease (Sundquist et al., 2006; Ali et al., 2006), and all-cause mortality (Lochner et al., 2003; Hutchinson et al., 2009). Social aspects of neighborhoods, such as trust, reciprocity, and collective efficacy, have also been associated with health outcomes (Kawachi et al., 1997; Sampson, 2003; Beard et al., 2009) including CHD outcomes (Sundquist et al., 2006; Chaix, 2009).

Additionally, urban sprawl may contribute to air and water pollution due to increased automobile emissions and environmental contamination caused by run-off from roadways, parking lots, construction sites, and other facets of sprawling development (Stone, 2008; Ewing, Pendall, and Chen, 2003; Tu et al., 2007). Reductions in green space and increases in blacktop surfaces associated with sprawl may also contribute to "heat islands" (Frumkin, 2002), which have been shown to increase mortality rates (Davis et al., 2003).

To date, studies considering the relationship between sprawl and adverse health outcomes other than obesity have found mixed results. Sturm and Cohen (2004) analyzed the relationship between urban sprawl and 16 self-reported chronic health conditions or symptom clusters, and found that sprawl was linked to five specific conditions including headaches and lung disease, as well as a higher number of total conditions reported. Sprawl was not associated with several conditions commonly linked to obesity, including diabetes, hypertension, and angina/heart disease. Doyle et al. (2006) similarly found that county-level "walkabililty" (a measure of how easy it is to walk as a mode of transportation) was related to neither diabetes nor hypertension, although it was associated with lower BMI. In contrast, Ewing et al. (2003) found a small but statistically significant relationship between countylevel sprawl and hypertension, and Mobley et al. (2006) found that low-income women living in mixed land-use environments had lower coronary heart disease (CHD) risk scores (measured using a composite index that included gender, age, cholesterol levels, systolic blood pressure, smoking status, and diabetes status) than similar women in single-use communities.

Heart disease is the leading cause of death for women in the United States, and accounted for 25 percent of all deaths among women and girls in 2007 (Centers for Disease Control, 2011). Yet, to date, no studies have assessed the relationship between urban sprawl and CHD endpoints, such as myocardial infarction (MI) and CHD death. Much of the literature on neighborhoods and health uses neighborhood socioeconomic status (NSES) as a summary measure of community attributes because NSES is correlated with both physical and social characteristics of neighborhoods (Diez-Roux et al., 2001; Winkleby, Sundquist, and Cubbin, 2007; Dubowitz et al., 2008). Further, the majority of studies, including all studies focusing on outcomes other than obesity and sprawl, have used cross-sectional data. 
In this study, we analyze the relationship between urban sprawl, all-cause mortality, and the occurrence of coronary heart disease (CHD) in a longitudinal population of women recruited at 40 clinical centers across the nation as part of the Women's Health Initiative (WHI) clinical trial (CT). The analysis focuses on metropolitan statistical area (MSA)-level compactness (the opposite of sprawl), assessed using an overall index as well as sub-indices measuring street connectivity, residential density, land use patterns, and the strength of the urban center or centers. We consider whether urban compactness measured at baseline is associated with a reduction in the occurrence of CHD in the WHI population, a geographically diverse cohort of post-menopausal women.

\section{Conceptual Framework}

In our analysis, we focus on the relationship between urban sprawl, which is a regional concept, and CHD outcomes. The American Planning Association (APA) defines sprawl as low density residential and commercial development at the outskirts of an urban area, and argues that "[c]haracteristics of sprawl include: ( a ) The premature or poorly planned conversion of rural land to urbanized uses; (b) urbanized development that is poorly connected to other land uses in the immediate area; and ( c ) urban development or uses that fail to maximize existing public facilities or that occurs outside areas where public services are currently planned for expansion" (APA, 2011). Other researchers have argued that a sprawling area is one that has "a population that is widely dispersed in a low density development, rigidly separated homes, shops, and workplaces; a network of roads marked by huge blocks and poor access; and a lack of well-defined, thriving activity centers, such as downtowns and town centers" (Ewing et al., 2002, pp. 3). Both definitions emphasize characteristics of suburban development built with the expectation that people will travel using cars, and with limited attention to how new development relates to the existing community.

The consequences of sprawl are not localized to suburban neighborhoods, but rather may accrue to an entire economic region, including areas within the region that are not themselves sprawling. Sprawl may increase traffic across a central city and its surrounding suburbs, as people commute to and from work. The increased pollution from traffic emissions will not necessarily be localized to the newly developed, outlying areas; rather, the pollution will accumulate differently across the region depending on traffic patterns, weather, geography, and other factors. Marshall et al. (2009) point out that it is possible for areas of low walkability to have low impacts from vehicle emissions since activities and emissions may end up being too dispersed to have an impact on outcomes; along the same lines, areas with high walkability may see larger impacts from vehicle emissions because of elevated traffic congestion caused by the overall layout of the region within which it resides. A similar argument holds for most of the other consequences of sprawl. As the geographic region expands commute times will increase, both due to more traffic and larger distances between prime destinations. Larger distances between destinations and increase traffic could make walking or biking less attractive for everyone, regardless of location within an economic area. Increased traffic may further reduce the attractiveness of cycling and walking due to the health hazards associated with traffic-related air pollution and automobile accidents (de Hartog et al., 2010). Sprawl may reduce opportunities to socialize after work, as fewer colleagues live within close proximity to places of business. Sprawl may also reduce the viability of public transportation, since more stops will be needed to serve a population of a given size, increasing both infrastructure costs and travel times.

Prior studies have used both metropolitan statistical area (MSA) and county as the geographic unit over which to measure sprawl. In this analysis, we focus on MSAs, which are defined by the US Office of Management and Budget to capture a central city and the 
surrounding counties that are economically and socially connected to this city. This approach to defining sprawl captures all of outlying development around an urban core, which, as hypothesized above, may have consequences for the entire economic area. Sprawl measures based on county, in contrast, will not capture the spillover effects of poorlyplanned suburban development that could accrue broadly across economically and socially connected areas captured by the MSA. Moreover, counties are administrative boundaries that are not measured in a consistent way from place to place. For example, Philadelphia County is coterminous with the city of Philadelphia, New York City is comprised of five separate counties, and many other cities, such as San Diego, are situated within a larger surrounding county.

Figure 1 demonstrates the pathways through which individual, neighborhood, and metropolitan area characteristics might influence CHD risk factors and, ultimately, CHD outcomes. In our analyses, we measure urban compactness (the opposite of sprawl) using a measure that captures the four MSA-level characteristics described in the lower left hand side of the figure. We control for many individual characteristics and neighborhood socioeconomic status (NSES). In sensitivity analyses, we add additional controls for specific features of the local environment, including neighborhood-level street connectivity and population density. We do not directly observe the CHD risk factors that may mediate the relationship between MSA (or neighborhood) level characteristics and CHD outcomes.

\section{Methods}

\section{Women's Health Initiative (WHI) Data}

Data for this analysis come from the WHI Clinical Trial (CT) which included 68,132 postmenopausal women aged 50 to 79 years at enrollment. Details of the study design have been described elsewhere (The Women's Health Initiative Study Group, 1998; The Women's Health Initiative Steering Committee, 2004; Hays et al., 2003; Stefanick et al., 2003). Participants were recruited between 1993 and 1998 in areas surrounding 76 examination sites and followed until March 2005 (mean $=7.5$ years). The WHI population was relatively healthy at baseline because the study excluded women with pre-existing health conditions including myocardial infarction (MI) or stroke in the past 6 months, severe hypertension (systolic blood pressure $>200 \mathrm{~mm} \mathrm{Hg}$ or diastolic blood pressure $>105 \mathrm{~mm} \mathrm{Hg}$ ), mental illness, or a predicted survival of less than three years (Hays et al., 2003).

Because the compactness index used in this analysis (the Rutgers-Cornell Index, described in more detail below) was available for only 59 MSAs in our sample, we excluded 16,178 women residing outside of MSAs or in MSAs without sprawl data. Additionally, we excluded 190 women due to missing outcome data, 784 women due to foreign or military addresses, and 5601 women due to missing street address or zip code.

\section{Compactness Measures}

We measured urban compactness using the Rutgers-Cornell Metropolitan Statistical Area (MSA)-level index developed by Ewing et al. (2002) and used in several prior studies considering the relationship between urban sprawl and population health (Ewing, Pendall, and Chen, 2003; Sturm and Cohen, 2004; Stone, 2008). The Rutgers-Cornell index is a composite measure reflecting four components of urban compactness including: 1) residential density; 2) mixed land use (e.g. neighborhood mix of homes, jobs and services); 3) street connectivity (e.g. accessibility of the street network); and 4) centeredness (e.g. strength of activity centers and downtowns). The measure is scaled so that it has a mean of 100 and a standard deviation of 25 . Because, in some cases, data used to develop the index are available only for large MSAs, the index is available only for 83 MSAs with populations 
exceeding 500,000. A complete description of the methods and data sources used for the index can be found in Ewing, Pendall, and Chen (2003).

Although the Rutgers-Cornell index is often referred to as a measure of sprawl, it is scaled so that less sprawling areas receive higher scores. For example, relative to all other MSAs in the country, New York City receives the highest overall score, and MSAs with low scores include Atlanta GA, Riverside CA, and Greensboro NC. We therefore refer to the RutgersCornell index as a measure of urban "compactness," which we hypothesize is associated with better health through avenues such as greater walkability, lower pollution, and higher social capital. MSAs with compactness values close to the mean value of 100 include San Diego, CA, Seattle, WA, and Los Angeles, CA. MSAs with compactness values close to 75 (one standard deviation below the mean) include Oxnard-Ventura, CA, Gary-Hammond, IN, and Rochester, NY. MSAs with compactness values close to 125 (one standard deviation above the mean) include Denver, CO, New Orleans, LA, and Miami-Hialeah, FL. The compactness index is based on data from a variety of sources and years mostly collected between 1990 and 2000 (Ewing, Pendall, and Chen, 2003). The time period over which compactness data were collected corresponds to the enrollment period for the WHI study (1993 to 1998). We use the compactness index at baseline to characterize sprawl over the entire follow-up period.

\section{Dependent Variables}

Our dependent variables included time from randomization until a) death by any cause, b) CHD death, c) CHD death or first myocardial infarction (MI) post-randomization, including silent MI ("CHD death or MI"), and d) first CHD event post-randomization where "events" include CHD death, MI (including silent MI), confirmed angina, and coronary revascularization (CABG or PCI). Each dependent variable was derived from the adjudicated WHI follow-up data updated through March 31, 2005.

Specifically, cardiovascular outcomes in the WHI were ascertained from semi-annual mailed surveys asking participants about treatment or hospitalization for "problems with the heart or circulation, stroke or transient ischemic attack (TIA)". Deaths were identified through communication with proxy respondents and the National Death Index. Detailed definitions of CHD outcomes, outcomes ascertainment, and adjudication methods have been published previously (Hsia et al., 2006; Manson et al., 2003; Howard et al., 2006; Curb et al, 2003). Medical documentation for all deaths and overnight hospitalizations were reviewed centrally by physician adjudicators (for CHD death) or trained local physician adjudicators (for other coronary end points). At least $10 \%$ of local adjudications were centrally reviewed for quality control. Agreement between the local and central adjudicators was good to excellent (kappa was 0.80 for MI, 0.67 for angina and 0.94 for coronary revascularization; Heckbert et al., 2004). Overall, a total of 3,009 women experienced a CHD event during the study follow-up period; 1,432 of these events were MI or CHD death, and 414 were CHD death. A total of 2,461 women died from any cause during the follow-up period.

\section{Independent Variables}

We created basic and extensive sets of individual-level control variables drawn from baseline data (shown in Table 1). The basic controls were characteristics for which we had theoretical reason to believe could be related to CHD development, but that were unlikely to be affected by sprawl in an individual's community. These characteristics, which were all measured as categorical variables, included: age groups ( 6 categories), randomization year (6 categories), race/ethnicity (4 categories), education (4 categories), income (8 categories), marital status (5 categories), family history of MI, and membership in the control and intervention arms of the hormone therapy (HT,), dietary modification (DM), and calcium- 
vitamin $\mathrm{D}(\mathrm{CaD})$ trials. In addition, the basic control model included a census-tract level measure of neighborhood socioeconomic status (NSES), which has previously been found to predict adverse health outcomes (Dubowitz 2008; Do et al., 2007; Bird et al. 2009). The NSES index is a summary measure reflecting (1) percent adults older than 25 with less than a high school education; (2) percent male unemployment; (3) percent households with income below the poverty line; (4) percent households receiving public assistance; (5) percent households with children headed only by a female; and (6) median household income. NSES and the sprawl measures were included as continuous variables.

The extensive set of controls added CHD risk factors that could potentially mediate the relationship between compactness and CHD outcomes. In general, these were characteristics that might themselves be influenced by sprawl in an individual's community, such as weekly calorie expenditure. Specifically, the extensive set of controls includes the basic controls plus current hormone use status (never used, past user, currently uses estrogen, currently using estrogen plus progestin), total number of pack-years smoked (measured continuously), level of current alcohol use (non-drinker, $<1$ drink per week, $1-7$ drinks per week, more than 7 drinks per week), categorized body-mass index (BMI; $<=18.5,18.6$ to $<24.9,25$ to 29.9, 30 to 34.9, and 35+), waist-hip ratio (WHR; measured continuously), a continuous measure of average weekly calorie expenditure estimated from self-report of physical activity, and indicators for diabetes, hypertension, and hyperlipidemia at baseline based on self-reported history, measured blood pressures, and current medication use. A limitation of the extensive control models is the lack of measured lipid values in all but a small sample of the WHI participants. Therefore, self-reported treatment with cholesterollowering drugs or the presence of cholesterol-lowering drugs in the medication inventory was used to measure hyperlipidemia.

On average, individual-level covariates were missing in $1.9 \%$ of cases. We imputed missing values of individual-level covariates using IVEware in SAS. Our primary models (using the basic and extensive set of individual level controls described above) include only the overall sprawl index as a neighborhood level predictor. Our secondary models examine each of the four components of the sprawl index (density, mixed land use, street connectivity, and centeredness) separately. To control for geographic variation, we included random effects due to MSA-level membership in our models as well as fixed effects for region (Northeast, South, Midwest, or West).

\section{Analysis}

We used Cox proportional hazards $(\mathrm{CPH})$ models with shared frailty parameters to examine the association between time from randomization until our outcomes and the compactness index. Shared frailty models were used to account for geographic clustering of women at the MSA level in the WHI CT data. Preliminary analyses showed no evidence of significant clustering of the outcomes by census tract and only very minimal evidence of clustering and heterogeneity of the outcomes by MSA. Nonetheless, an MSA-level shared frailty was used in the models to ensure more robust inferences across the different geographic regions represented in the WHI CT. The general shared frailty model we estimated was:

$$
h_{i k}(t)=h_{o}(t) \rho_{k} \exp \left(x_{i k} \beta\right)
$$

where $\rho_{\mathrm{k}}$ denotes the MSA-level frailty, $\mathrm{x}_{\mathrm{ik}}$ denotes the vector of individual-level and neighborhood level covariates for individual i living in MSA $\mathrm{k}$, and $t$ denotes the time scale (time since randomization). The MSA-level frailty was assumed to be a gamma frailty with mean of unity and variance $\theta$. 
In our analysis of age at CHD death, a competing risk shared frailty model was used to account for the fact that some individuals who might have died from CHD ended-up dying from other causes first. Here, deaths were grouped into two categories: death due to CHD and death from all other causes; the results shown only report the hazard ratios (HR) and 95\% confidence intervals (CI) for the effect of the urban compactness index and its four components on the cause-specific hazard for death by CHD.

All analyses were fit using R's coxme command and the assumption of proportional hazards for all covariates was tested using the cox.zph command in $\mathrm{R}$ and examining plots of the weighted Schoenfeld residuals (Gambsch and Therneau, 1994). Due to evidence of nonproportionality, all models stratified on age groups and $\mathrm{CaD}$ intervention arm indicators while additional stratification variables varied depending on the outcome being modeled. Models for all cause death stratified on HT arm indicators, hypertension, diabetes and hyperlipidemia; models for CHD event stratified on family history of MI and education; models for CHD death or MI stratified on HT arm indicators, family history of MI and current hormone use status; models for CHD death stratified on hypertension and diabetes.

\section{Sensitivity Analyses}

A potential concern regarding neighborhood research is the possibility that individuals selfselect into neighborhoods, creating a spurious correlation between the compactness index and subsequent health outcomes. We attempt to address this potential bias by implementing two types of sensitivity analyses. In the first, we implemented propensity score weighted versions of our basic and extensive control models, using methods that have been developed for binary independent variables to balance the distribution of individual-level covariates across our 83 MSAs (the level at which urban sprawl is measured). Specifically, the propensity score weights used in our analyses were computed using Generalized Boosted Models (GBM, McCaffrey et al., 2004) a flexible, non-parametric estimation technique that can account for a large number of baseline covariates (e.g. the extensive set of controls described above). For each MSA, we regressed an indicator of whether or not a woman lived in that MSA on our independent variables from the extra control model described above, excluding the compactness and NSES measures. Then, for each woman in that MSA, we assigned population weights equal to 1 over the predicted probability that the woman actually lived in the MSA in question. This weighting scheme has the effect of making women within each MSA have individual level covariates with a similar distribution to the entire population of women in our analysis, thereby ensuring the MSAs are balanced across the extensive set of individual level covariates used in our models. Propensity weight estimation is implemented using the "twang" package in R (Ridgeway et al., 2006).

Because propensity score methods can only address the effects of selection due to observed covariates, we also implemented a sensitivity analysis to address the potential biases that may result in our analyses from unobserved heterogeneity (Rosenbaum and Rubin, 1983; Lin et al., 1998; Higashi et al., 2005). In particular, we performed a simulation study to assess the potential effects of an omitted confounder variable on our results. We assumed the omitted variable is binary, negatively correlated with the CHD outcomes considered, and positively correlated with the compactness index. The goal of the simulation study was to determine what levels of correlation would be required for an omitted confounder to explain our results.

As articulated in our conceptual framework, we believe that urban compactness is most appropriately defined at the MSA level, rather than at a smaller geographic level such as county or census tract. However, we conducted additional sensitivity analyses to assess the implications of defining our urban compactness measures at the MSA-level. First, we replaced the MSA-level compactness index with a county-level compactness index that was 
also developed by the Rutgers-Cornell research group (Ewing et al., 2003). Second, we added census-tract level measures of street connectivity ${ }^{1}$ and residential density to our models, to determine if the inclusion of these localized variables influenced the relationship between MSA-level compactness measures and CHD outcomes.

Finally, exploratory models were fit which assessed whether the effect of the overall compactness scale was moderated by individual income, ethnicity, age, and region. Interactions for each of these potential moderators were assessed independently of one another and added to the regression models which only included our basic set of controls.

\section{Results}

The study population $(n=45,376)$ was $78.6 \%$ non-Hispanic white, $11.4 \%$ non-Hispanic black, 5.4\% Hispanic, and 4.7\% other (Table 1). Overall, 59.6\% were married at baseline, 94.3\% had at least a high school education, and $63.1 \%$ had household incomes lower than $\$ 50,000$ at baseline. Compactness variables shown in the table are averaged across women in the WHI study population, so the mean and standard deviation are no longer 100 and 25, as is the case when the variable is averaged across MSAs.

Women who were excluded from the analysis were different from those included in that excluded women were more likely to have experienced a CHD event, more likely to be white, more likely to have a lower income, less likely to have an advanced degree, and more likely to be married. Appendix Table A.1 shows differences between the included and excluded populations. In general, the differences between excluded and included women are not surprising given that excluded women were more likely to be rural or from small MSAs. However, the exclusion criteria may limit the generalizability of our results.

Table 2 presents adjusted hazard ratios from the basic (Model A) and extensive control (Model B) models for each of the four outcomes by the compactness index and its four components. These hazard ratios represent the effect seen for a one standard deviation increase in each measure (i.e., a 25-point change). As shown in the first column, living in a more compact area is significantly associated with a decreased risk of CHD event and CHD death or MI $(\mathrm{HR}=0.95,95 \% \mathrm{CI}=0.995,1.00 ; \mathrm{HR}=0.92,95 \% \mathrm{CI}=0.86,0.98$, respectively, in Model A). These results suggest that women living in areas with a lower degree of compactness (or higher urban sprawl) are at significantly higher risk of CHD events or CHD death or MI than those living in more compact areas. These results are robust to the inclusion of the more extensive controls in Model B ( $\mathrm{HR}=0.95,95 \% \mathrm{CI}=0.91,0.99$ for any $\mathrm{CHD}$ event; $\mathrm{HR}=0.92,95 \% \mathrm{CI}=0.86,0.98$ for $\mathrm{CHD}$ death or MI). There was no significant association between the compactness index and all-cause mortality or CHD death.

To illustrate the magnitude of these effects, MSAs near the 10th decile of the index include Oxnard-Ventura, CA, Fort Worth-Arlington, TX, and Gary-Hammond, IN, and MSAs near the 90th decile of the index include Denver, CO, Portland, OR, and Boston, MA. Our analysis suggests that moving from a sprawling community such as Oxnard-Ventura to a more compact community like Boston, MA, would be associated with an 11 percent decrease in the hazard of any CHD event $(95 \% \mathrm{CI}=2 \%, 21 \%)$ and an 19 percent decrease in the hazard of CHD death or MI $(95 \% \mathrm{CI}=5 \%, 35 \%)$.

\footnotetext{
${ }^{1}$ Street connectivity was measured using the alpha and gamma indices. See Berrigan, Pickle, and Dill (2010) for a more complete definition of these variables.
} 
The last four columns of Table 2 report the relationship between individual components of urban compactness (street connectivity, residential density, mixed land use, and MSAcenteredness) and CHD outcomes. Hazard ratio estimates are less than one for any CHD event and CHD death or MI for all four of the component indices; however, results are only statistically significant for two of the component indices. First, greater residential density is inversely associated with both any CHD event and CHD death or MI. Second, greater mixed land use is inversely associated with CHD death or MI in both models. The residential density findings indicate that women who live in denser communities are at a lower risk for any CHD event $(\mathrm{HR}=0.94,95 \% \mathrm{CI}=0.91,0.97)$ and $\mathrm{CHD}$ death or $\mathrm{MI}(\mathrm{HR}=0.90 ; 95 \% \mathrm{CI}$ $=0.86,0.95$ ). Together, all four components of the compactness index may be related to improved CHD outcomes, but residential density is the most notable independent predictor. Again, results are robust to the inclusion of the extensive control set.

\section{Sensitivity Analyses}

Propensity analyses (results not shown) confirmed that the effect sizes in the models presented were not sensitive to selection on observed characteristics. In Figure 2, we show results from the correlation analysis for the outcome "time to any CHD event." Graphically, the figure plots a frontier line showing the minimum correlations an omitted variable would need to have with both the outcome (whether the respondent experienced a CHD event) and the independent variable (compactness) in order to explain the results reported in Table 2. The dots plotted against this line show the observed correlations that exist in the data, for all of the individual-level variables included in our extensive control models. The figure indicates that, for an unobserved individual characteristic to explain our results, the correlations between this variable, urban compactness, and CHD would need to be higher than the correlations that exist for any of the observed covariates, including age, hypertension, and diabetes.

When we replaced the MSA-level compactness variables with county-level variables, the main conclusions - that CHD outcomes are better in more compact communities-were unchanged. Adding census tract level street connectivity and residential density measures to the models did not change the magnitude or statistical significance of the MSA-level compactness results (see Appendix Table A.2 for details).

In additional sensitivity analyses, we tested whether our results changed after we excluded a relatively small number $(\mathrm{N}=2705)$ of women who had a CHD event prior to entry into the WHI study. These exclusions altered neither the sign nor the significance of the results. We opted to report the analyses including women with a prior history of CHD because the theoretical pathways through which urban compactness might affect CHD outcomes are relevant for both incident and recurrent CHD outcomes.

Table 3 presents adjusted hazard ratios from exploratory models including interactions between putative moderators (race/ethnicity; income; region; age) and the overall compactness index. The tabulated hazard ratios represent effects per one standard deviation increase in compactness within each subgroup of interest. There was evidence of significant moderation by race/ethnicity with black non-Hispanics experiencing the largest protective effects of compactness for CHD event and CHD death or $\mathrm{MI}(\mathrm{HR}=0.88,95 \% \mathrm{CI}=0.80$, $0.98 ; \mathrm{HR}=0.83,95 \% \mathrm{CI}=0.71,0.97$, respectively). For white non-Hispanics there was marginal evidence of a protective effect of compactness on these outcomes, although the size of the protective effect is lower than that for black non-Hispanics $(\mathrm{HR}=0.97,95 \% \mathrm{CI}=$ $0.93,1.02 ; \mathrm{HR}=0.93,95 \% \mathrm{CI}=0.87,1.00$, respectively). The confidence intervals for the Hispanic and other race/ethnic groups were too large to be conclusive about how compactness is likely to impact women within them. 
Table 3 also shows that there were significant interactions between region and compactness for CHD event and CHD death or MI. Women living in the Northeast experienced the largest protective effects of compactness $(\mathrm{HR}=0.86,95 \% \mathrm{CI}=0.81,0.91 ; \mathrm{HR}=0.84,95 \%$ $\mathrm{CI}=0.76,0.91$, respectively). Power in other regions was limited but hazard ratios were all notably closer to 1.00 for these outcomes. No significant income- or age-compactness interactions were found although the $95 \%$ confidence intervals for each income and age group illustrate the limited power of detecting such interactions in this context.

\section{Discussion}

Prior research has found a link between urban sprawl and obesity. However, few studies have considered the relationship between sprawl and other health outcomes, and those that have addressed this question have found mixed results. Most studies that have considered the relationship between sprawl and CHD or CHD-related outcomes such as diabetes and hypertension have relied on self-reported conditions, and have found little or no relationship (Ewing, Pendall, and Chen, 2003; Sturm et al., 2004; Doyle et al, 2006). One study that used a CHD risk score measure based on biometric data did find a link between sprawl and CHD (Mobley et al., 2006), however this study was limited to low-income women. In this current analysis, we use longitudinal data to assess the relationship between urban compactness and CHD endpoints among women aged 50-79 years at baseline. CHD is a particularly important outcome in this context because it is the leading cause of death among women, and a potential consequence of other outcomes such as obesity that have been previously linked to sprawl.

We find that there is a relationship between urban compactness (which is the inverse of sprawl) and CHD outcomes-particularly "any CHD event" and "CHD death or MI." While the absolute magnitude of the effect is relatively small when comparing women living in MSA's whose compactness measure is one standard deviation apart (e.g., hazard ratios in Table 2 are close to 1), the impact is larger when comparing women from the highest and lowest deciles of compactness (e.g., yielding an 11 percent difference in hazard for CHD event, and a 19 percent change in the hazard for CHD death or MI).

A critique raised in previous studies is that individuals with preferences for a more sedentary lifestyle might opt to live in more sprawling areas (Plantinga and Bernell, 2007). Lee et al. (2009) find that relationships between sprawl, obesity, and physical activity that were statistically significant in cross-sectional models could not be reproduced in longitudinal analyses, suggesting that sedentary people may self select into sprawling neighborhoods. However, our analysis suggests that the relationship between compactness and CHD remains even after adjusting for obesity and weekly calorie expenditure. Moreover, the plots shown in Figure 2 indicate that the degree of correlation between an omitted variable (e.g. preference for a sedentary lifestyle) and the key dependent and independent variables used in this study would need to be stronger than the degree of correlation found for any of the observed covariates to explain the results.

The main covariate considered in this analysis is an MSA-level measure of urban compactness. Because MSAs are large geographic regions, the key predictors used in this analysis do not reflect an individual's immediate neighborhood surroundings. Numerous studies have found that neighborhood-level socioeconomic disadvantage is associated with poor health outcomes, including CHD outcomes. For example, using data from the Atherosclerosis Risk in Communities (ARIC) study, Diez Roux et al. (2001) found than individuals living in more disadvantaged census block groups (as defined by income, wealth, occupation, and education), were more likely to experience CHD death or MI than their counterparts over a 9 year follow-up period. Other studies have found similar 
associations between neighborhood socio-economic status and CHD using different populations and alternative measures of neighborhood disadvantage (LeClere et al. 1998; Sundquist et al., 2004; Winkleby et al., 2007; Chaix et al., 2007). Sprawl is a different concept than neighborhood disadvantage, and must be measured at a geographic level larger than the immediate neighborhood in order to fully capture the milieu in which individuals might work, shop, socialize, and live. Localized sprawl in one portion of an MSA might contribute to higher pollution levels throughout the MSA, or could cause localized pollution in a less-sprawling part of the MSA. Sprawling development might also affect health across the MSA by causing longer commute times, making it more difficult to socialize due to large spatial separations between both houses and neighborhoods, or by inhibiting the use of bicycles and public transportation. Using the same MSA-level compactness index considered in this study, Stone (2008) found an association between sprawl and excessive ozone levels. Another study (Rashad et al., 2001) found an association between the compactness index used in this analysis and the prevalence of bicycling.

Although sprawling development at any place within an MSA may have consequences for the entire economic area, it is not clear that these consequences will accrue equally to all members of the community. Traffic emissions and traffic noise may be felt most acutely along major thoroughfares and in low-lying areas, even if these areas are not themselves sprawling. Marshall et al. (2009) found evidence that low-income urban areas tend to have both higher walkability and higher exposure to nitric oxide than the higher income suburbs, suggesting that individuals who are poor bear a disproportionate burden of traffic pollution even when they reside in walkable communities. Our moderation analyses provide an exploratory examination of which individuals are most affected by sprawl. In them, we find preliminary evidence of significant moderation by race/ethnicity and region with black nonHispanics and women residing in the Northeast experiencing the greatest protective effects of decreasing sprawl (or increasing compactness). However, these analyses had limited power for most sub-groups, particularly income and age groups; additional research should explore the possibility that certain sub-groups, such as those who are socioeconomically disadvantaged, are the most negatively affected by MSA-level sprawl.

An additional limitation of this analysis is that we are unable to explain the mechanisms by which urban compactness would have beneficial implications for CHD health. We hypothesized that better opportunities to walk in more compact areas, perhaps due to more sidewalks or more nearby walking destinations, would explain the results. Yet, our findings are virtually unchanged after controlling for a variety of health behaviors and intermediate health outcomes including both calorie expenditure and BMI. The lack of a clear pathway linking urban sprawl to health outcomes makes it difficult to recommend specific policy options for improving coronary health.

Nonetheless, our analysis suggests that "smart growth" initiatives underway in communities across the country, such as focusing new development in existing areas and investing in public transportation, may have public health benefits. Despite the inability to explain the mechanisms linking urban compactness and improved CHD outcomes, our study also has several strengths including the fact that we consider all-cause mortality and the occurrence of CHD in a population of women who were relatively healthy at baseline, rather than looking at cross-sectional relationships between compactness and existing illness. An additional strength of our approach is that CHD outcomes data in the WHI were confirmed by review of medical records, reducing any potential bias that might stem from asking respondents to self-report adverse health outcomes. Moreover, we can observe both morbidity and mortality related to CHD. Future work will be necessary to determine why urban compactness is predictive of improved CHD outcomes. Additional explanations that warrant further consideration include the role of pollution, social capital, and stress. While it 
may be premature to propose specific policy solutions to reduce urban sprawl given that the pathways linking sprawl and health are incompletely understood, this research adds to a growing body of evidence suggesting that urban design can have significant implications for population health.

\section{References}

Ali S, Merlo J, Rosvall M, Lithman T, Lindstrom M. Social capital, the miniaturisation of community, traditionalism and first time acute myocardial infarction: a prospective cohort study in southern Sweden. Social Science and Medicine. 2006; 63:2204-2217. [PubMed: 16797808]

American Planning Association (APA) Fact Sheet. [Accessed March 25, 2011] Public Health Terms for Planners and Planning Terms for Public Health Professionals. Available at: http:// www.planning.org/research/healthy/pdf/jargonfactsheet.pdf

Beard JR, Blaney S, Cerda M, Frye V, Lovasi GS, Ompad D, Rundle A, Vlahov D. Neighborhood characteristics and disability in older adults. Journal of Gerontology: Social Sciences. 2009; 64(B): 252-257.

Berrigan D, Pickle LW, Dill J. Associations Between Street Connectivity and Active Transportation. International Journal of Health Geographics. 2010; 9:1-18. [PubMed: 20082711]

Besser L, Marcus M, Frumkin H. Commute time and social capital in the U.S. American Journal of Preventive Medicine. 2008; 34:207-211. [PubMed: 18312808]

Bird C, Seeman T, Escarce J, Basurto-Davila R, Finch B, Dubowitz T, Heron M, Hale L, Merkin S, Weden M, Lurie N. Neighborhood socioeconomic status and biological "wear \& tear" in a nationally representative sample of U.S. adults. Journal of Epidemiology and Community Health. 2009

Centers for Disease Control (CDC). [accessed March 28, 2011] Deaths, percent of total deaths, and death rates for the 15 leading causes of death in 5-year age groups, by race and sex: United States 2007. National Vital Statistics System. 2011. Available online at: http://www.cdc.gov/nchs/data/ dvs/LCWK1_2007.pdf

Chaix B, Rosvall M, Merlo J. Neighborhood socioeconomic deprivation and residential instability: effects on incidence of ischemic heart disease and survival after myocardial infarction. Epidemiology. 2007; 18:104-111. [PubMed: 17130687]

Chaix B. Geographic life environments and coronary heart disease: a literature review, theoretical contributions, methodological updates, and a research agenda. Annual Review of Public Health. 2009; 30:81-105.

Curb J, McTiernan A, Heckbert S, Kooperberg C, Stanford J, Nevitt M, Johnson K, Proulx-Burns L, Pastore L, Criqui M, Daugherty S. Outcomes ascertainment and adjudication methods in the Women's Health Initiative. Annals of Epidemiology. 2003; 13:S122-128. [PubMed: 14575944]

Davis R, Knappenberger P, Michaels P, Novicoff W. Changing heat-related mortality in the United States. Environmental Health Perspectives. 2003; 111:1712-1718. [PubMed: 14594620]

De Hartog JJ, Boogaard H, Nijland H, Hoek G. Do the health benefits of cycling outweigh the risks? Environmental Health Perspectives. 2010; 118:1109-1116. [PubMed: 20587380]

Do P, Dubowitz T, Bird C, Lurie N, Escarce J, Finch B. Neighborhood context and ethnicity differences in body mass index: a multilevel analysis using the NHANES III Survey (1988-1994). Economics and Human Biology. 2007; 5:179-203. [PubMed: 17507298]

Diez Roux AV, Merkin SS, Arnett D, Chamblass L, Massing M, Nieto J, Sorlie P, Szklo M, Tyroler H, Watson RL. Neighborhood of residence and incidence of coronary heart disease. New England Journal of Medicine. 2001; 345:99-106. [PubMed: 11450679]

Doyle S, Kelly-Schwartz A, Schlossberg M, Stockard J. Active environments and health. Journal of the American Planning Association. 2006; 72:19-31.

Dubowitz T, Heron M, Bird C, Lurie N, Finch B, Basurto-Davila R, et al. Neighborhood socioeconomic status and fruit and vegetable intake among whites, blacks, and Mexican Americans in the United States. American Journal of Clinical Nutrition. 2008; 87:1883-1891. [PubMed: 18541581] 
Ewing, R.; Pendall, R.; Chen, D. Measuring sprawl and its impact. Smart Growth America; Washington D.C: 2002.

Ewing R, Pendall R, Chen D. Measuring sprawl and its transportation impacts. Transportation Research Record. 2003; 1831:175-183.

Ewing R, Schmid T, Killingsworth R, Zlot A, Raudenbush S. Relationship between urban sprawl and physical activity, obesity, and morbidity. American Journal of Health Promotion. 2003; 18(1):4757. [PubMed: 13677962]

Ewing R, Brownson R, Berrigan D. Relationship between urban sprawl and weight of United States youth. American Journal of Preventive Medicine. 2006; 31:464-474. [PubMed: 17169708]

Frumkin H. Urban Sprawl and Public Health. Public Health Reports. 2002; 117:201-214. [PubMed: 12432132]

Fujiwara T, Kawachi I. Social capital and health: a study of adult twins in the United States. American Journal of Preventive Medicine. 2008; 35:139-144. [PubMed: 18617082]

Grambsch P, Therneau T. Proportional hazards tests and diagnostics based on weighted residuals. Biometrika. 1994; 81:515-526.

Hays J, Hunt J, Hubbell F, Anderson G, Limacher M, Allen C, Rossouw J. The women's health initiative: recruitment methods and results. Annals of Epidemiology. 2003; 13:S18-77. [PubMed: 14575939]

Heckbert S, Kooperberg C, Safford M, Psaty B, Hsia J, McTiernan A, Gaziano J, Frishman W, Curb J. Comparison of self-report, hospital discharge codes, and adjudication of cardiovascular events in the Women's Health Initiative. American Journal of Epidemiology. 2004; 160:1152-1158. [PubMed: 15583367]

Higashi T, Shekelle P, Adams J, Camberg C. Quality of care is associated with survival in vulnerable older populations. Annals of Internal Medicine. 2005; 143:274-281. [PubMed: 16103471]

Howard B, Van Horn L, Hsia J, Manson J, Stefanick M, Wassertheil-Smoller S, et al. Low-fat dietary pattern and risk of cardiovascular disease: The women's health initiative randomized controlled dietary modification. The Journal of the American Medical Association. 2006; 295:655-666.

Hsia J, Langer R, Manson J, Kuller L, Johnson K, Hendrix S, et al. Conjugated equine estrogens and coronary heart disease: The Women's Health Initiative. Archives of Internal Medicine. 2006; 166:357-365. [PubMed: 16476878]

Hutchinson R, Putt M, Dean L, Long J, Montagnet C, Armstrong K. Neighborhood racial composition, social capital and black all-cause mortality in Philadelphia. Social Science and Medicine. 2009; 68:1859-1865. [PubMed: 19324485]

Kawachi I, Kennedy BP, Lochner K, Prothrow-Stith D. Social capital, income inequality, and mortality. American Journal of Public Health. 1997; 87:1491-8. [PubMed: 9314802]

Kawachi I, Kennedy B, Glass R. Social capital and self-rated health: a contextual analysis. American Journal of Public Health. 1999; 89:1187-1193. [PubMed: 10432904]

Kim D, Subramanin S, Kawachi I. Bonding versus bridging social capital and their associations with self-rated health: a multi-level analysis of 40 US communities. Journal of Epidemiology and Community Health. 2006; 60:116-122. [PubMed: 16415259]

Kom E, Graubard B, Midthune D. Time-to-event analysis of longitudinal follow-up of a survey: choice of the time-scale. American Journal of Epidemiology. 1997; 145:72-80. [PubMed: 8982025]

LeClere FB, Rogers RG, Peters K. Neighborhood social context and racial differences in women's heart disease mortality. Journal of Health and Social Behavior. 1998; 39:91-107. [PubMed: 9642901]

Lee I, Ewing R, Sesso H. The built environment and physical activity levels: the Harvard alumni health study. American Journal of Preventive Medicine. 2009; 37:293-298. [PubMed: 19765500]

Lin D, Psaty B, Kronmal R. Assessing the sensitivity of regression results to unmeasured confounders in observational studies. Biometrics. 1998; 54:948-963. [PubMed: 9750244]

Lochner K, Kawachi I, Brennan R, Buka S. Social capital and neighborhood mortality rates in Chicago. Social Science and Medicine. 2003; 56:1797-1805. [PubMed: 12639596]

Lopez R. Urban sprawl and risk for being overweight or obese. American Journal of Public Health. 2004; 94:1574-1579. [PubMed: 15333317] 
Manson J, Hsia J, Johnson K, Rossouw J, Assaf A, Lasser N, et al. Estrogen plus progestin and the risk of coronary heart disease. New England Journal of Medicine. 2003; 349:523-534. [PubMed: 12904517]

Marshall JD, Brauer M, Frank LD. Healthy neighborhoods: walkability and air pollution. Environmental Health Perspectives. 2009; 117(11):1752-1759. [PubMed: 20049128]

McCaffrey D, Ridegway G, Morral A. Propensity score estimation with boosted regression for evaluating causal effects in observational studies. Psychological Methods. 2004; 9:403-425. [PubMed: 15598095]

Mobley L, Root E, Finkelstein E, Khavjou O, Farris R, Will J. Environment, obesity, and cardiovascular disease risk in low-income women. American Journal of Preventive Medicine. 2006; 30:327-332. [PubMed: 16530620]

Papas MA, Alberg AJ, Ewing R, Helzlsouer KJ, Gary TL, Klassen AC. The built environment and obesity. Epidemiologic Reviews. 2007; 29:129-143. [PubMed: 17533172]

Plantinga A, Bernell S. The association between urban sprawl and obesity: is it a two-way street? Journal of Regional Science. 2007; 47:857-879.

Putnam, R. Bowling alone. Simon \& Schuster; New York: 2000.

Ridgeway, G.; McCaffrey, D.; Morral, A. Toolkit for the weighted analysis of nonequivalent groups: a tutorial for the twang package. 2006.

Rashad I. Associations of cycling with urban sprawl and the gasoline price. American Journal of Health Promotion. 2009; 24:27-36. [PubMed: 19750960]

Rosenbaum P, Rubin D. Assessing sensitivity to an unobserved binary covariate in an observational study w/binary outcome. Journal of the Royal Statistical Society. 1983; 45:212-218.

Ross N, Tremblay S, Khan S, Crouse D, Tremblay M, Berthelot J. Body mass index in urban Canada: neighborhood and metropolitan area effects. American Journal of Public Health. 2007; 97:500508. [PubMed: 17267734]

Rundle A, Roux A, Free L, Miller D, Neckerman K, Weiss C. The urban built environment and obesity New York City: a multilevel analysis. American Journal of Health Promotion. 2007; 21:326-334. [PubMed: 17465178]

Saelens BE, Handy SL. Built Environment Correlates of Walking: A Review. Medicine and Science in Sports and Exercise. 2008; 40:S550-S566. [PubMed: 18562973]

Saelens B, Sallis J, Black J, Chen D. Neighborhood-based differences in physical activity: an environment scale evaluation. American Journal of Public Health. 2003; 93:1552-1558. [PubMed: 12948979]

Sampson RJ. The neighborhood context of wellbeing. Perspectives in Biology and Medicine. 2003; 46:S54-S64.

Stefanick M, Cochrane B, Hsia J, Barad D, Liu J, Johnson S. The Women's Health Initiative postmenopausal hormone trials: overview and baseline characteristics of participants. Annals of Epidemiology. 2003; 13:S78-86. [PubMed: 14575940]

Stone B. Urban sprawl and air quality in large US cities. Journal of Environmental Management. 2008; 86:688-698. [PubMed: 17368703]

Sturm R, Cohen D. Suburban sprawl and physical and mental health. Public Health. 2004; 118:488496. [PubMed: 15351221]

Suminski R, Poston W, Petosa R, Stevens E, Katzenmoyer L. Features of the neighborhood environment and walking by U.S. adults. American Journal of Preventive Medicine. 2005; 28:149-155. [PubMed: 15710269]

Sundquist K, Winkleby M, Ahlen H, Johansson S. Neighborhood Socioeconomic Environment and Incidence of Coronary Heart Disease: A Follow-Up Study of 25,319 Women and Men in Sweden. American Journal of Epidemiology. 2004; 159:655-662. [PubMed: 15033643]

Sundquist J, Johannson S, Yang M, Sundquist K. Low linking social capital as a predictor of coronary heart disease in Sweden: a cohort study of 2.8 million people. Social Science and Medicine. 2006; 62:954-963. [PubMed: 16081195]

Thiebaut A, Benichou J. Choice of time-scale in Cox's model analysis of epidemiologic cohort data: a simulation study. Statistics in Medicine. 2004; 23:3803-3820. [PubMed: 15580597] 
Tu J, Xia Z, Clarke K, Frie A. Impact of urban sprawl on water quality in eastern Massachusetts, USA. Environmental Management. 2007; 40:183-200. [PubMed: 17557170]

The Women's Health Initiative Study Group. Design of the Women's Health Initiative clinical trial and observational study. Controlled Clinical Trials. 1998; 19:61-109. [PubMed: 9492970]

The Women's Health Initiative Steering Committee. Effects of conjugated equine estrogen on postmenopausal women with hysterectomy: the Women's Health Initiative randomized controlled trial. The Journal of the American Medical Association. 2004; 291:1701-1712.

Vandergrift D, Yoked T. Obesity rates, income, and suburban sprawl: an analysis of US states. Health \& Place. 2004; 10:221-229. [PubMed: 15177197]

Winkleby M, Sundquist K, Cubbin C. Inequities in CHD incidence and case fatality by neighborhood deprivation. American Journal of Preventive Medicine. 2007; 32:97-106. [PubMed: 17234484] 
Individual Characteristics

\begin{tabular}{|l|c|}
\hline Age and Race/Ethnicity \\
Family History \\
Individual Socioeconomic Status \\
Other Individual Characteristics
\end{tabular}

Figure 1.

Conceptual Framework' 


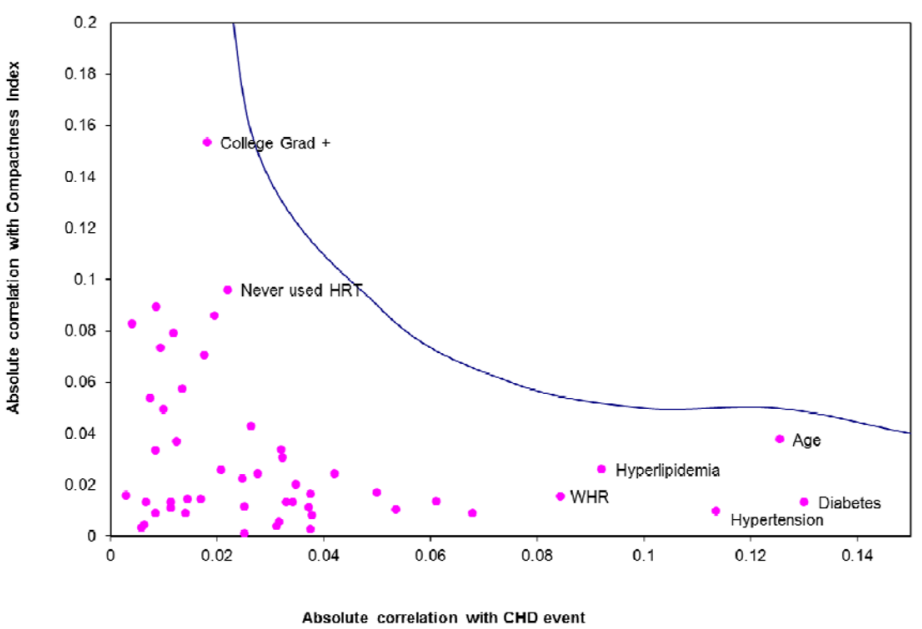

Figure 2.

'Frontier' plot for the omitted variable analysis of CHD event. 


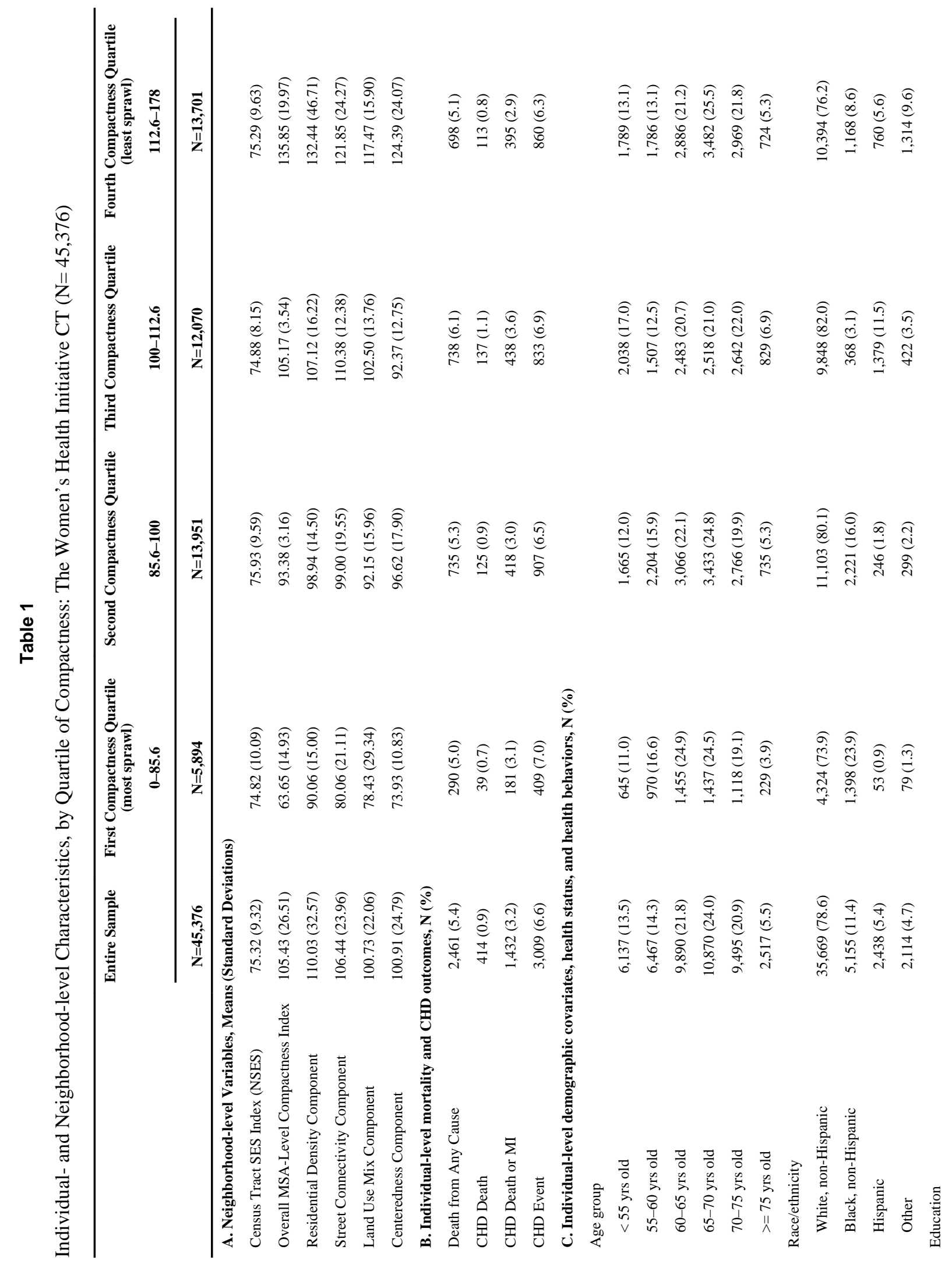




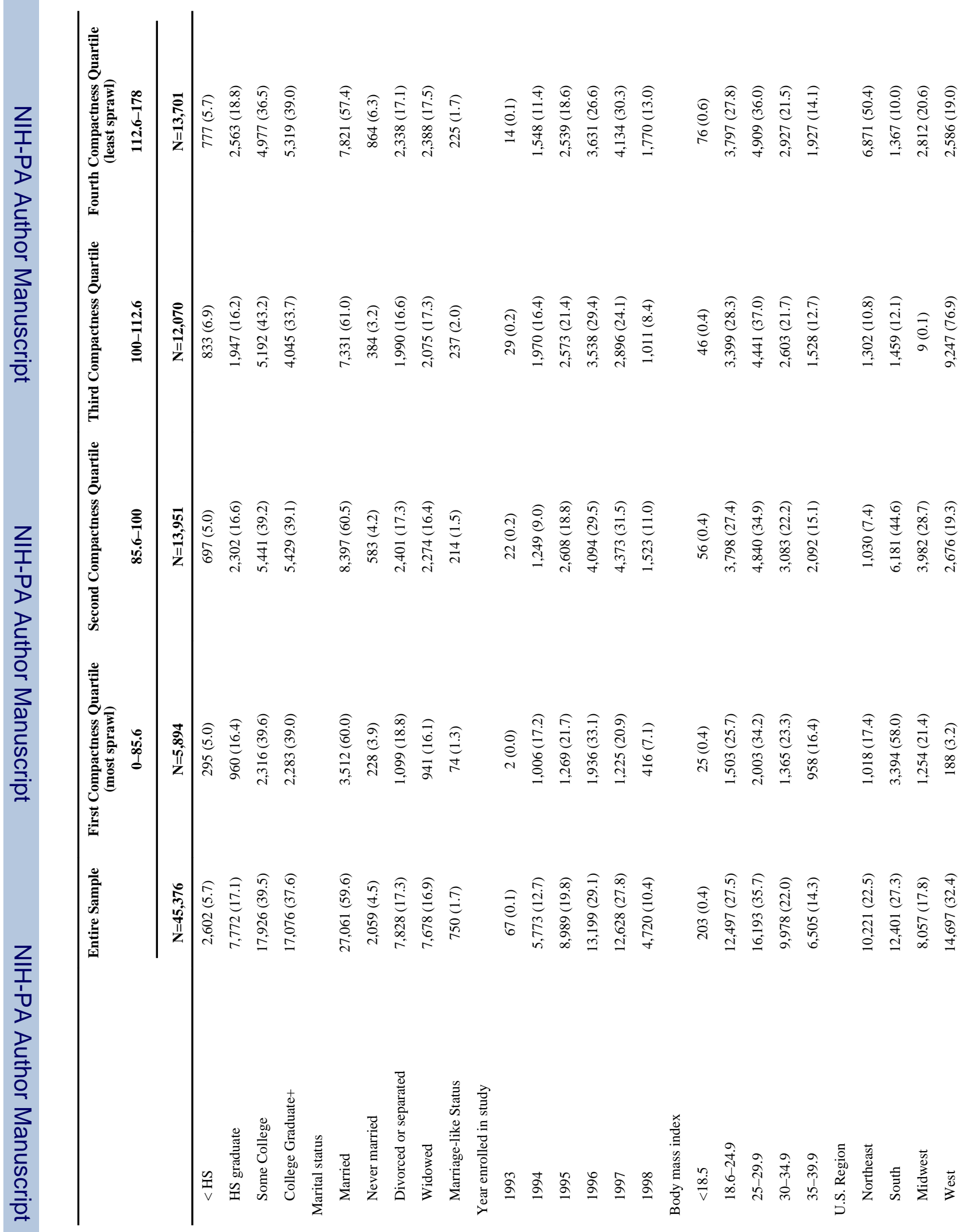




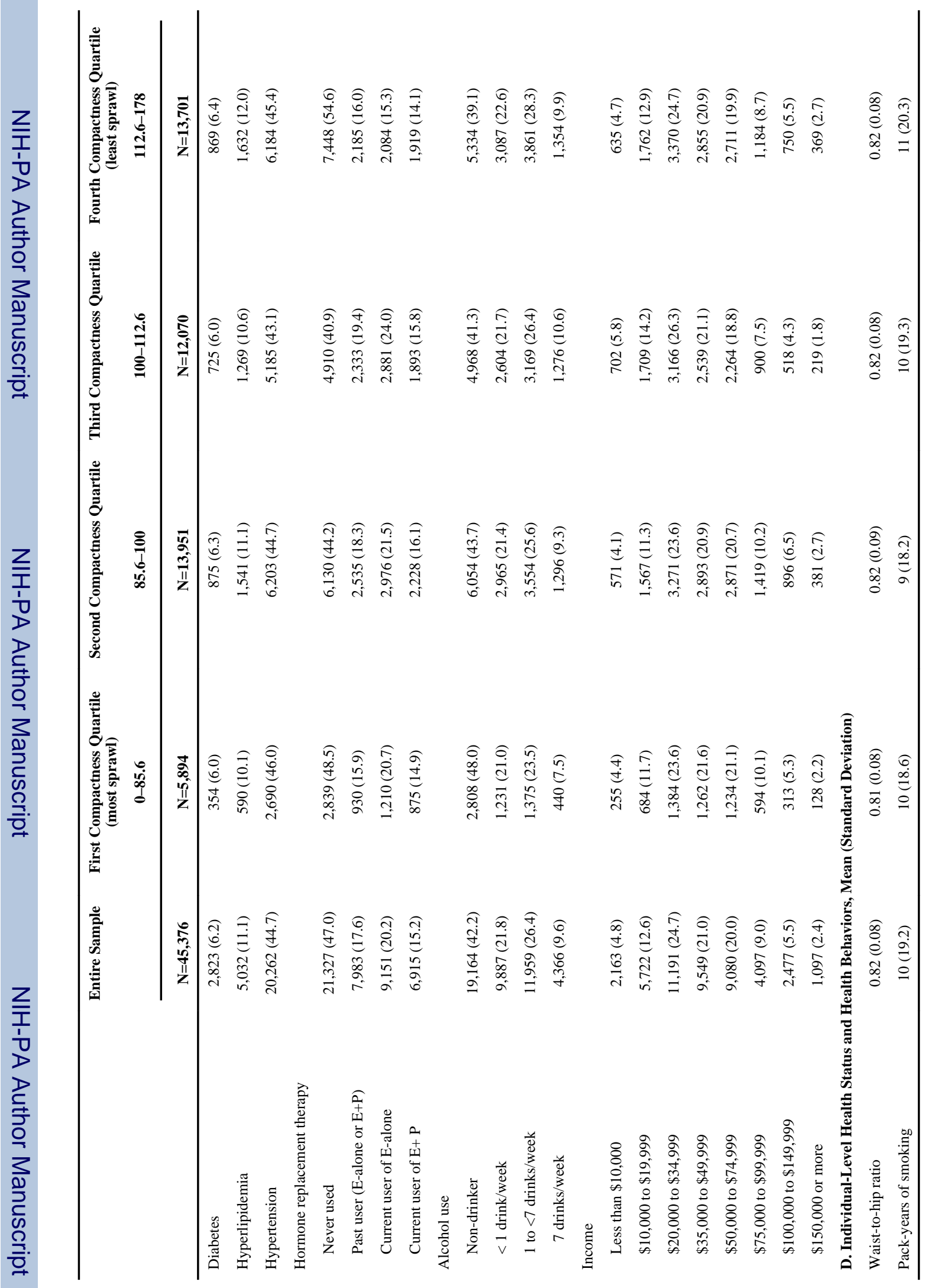




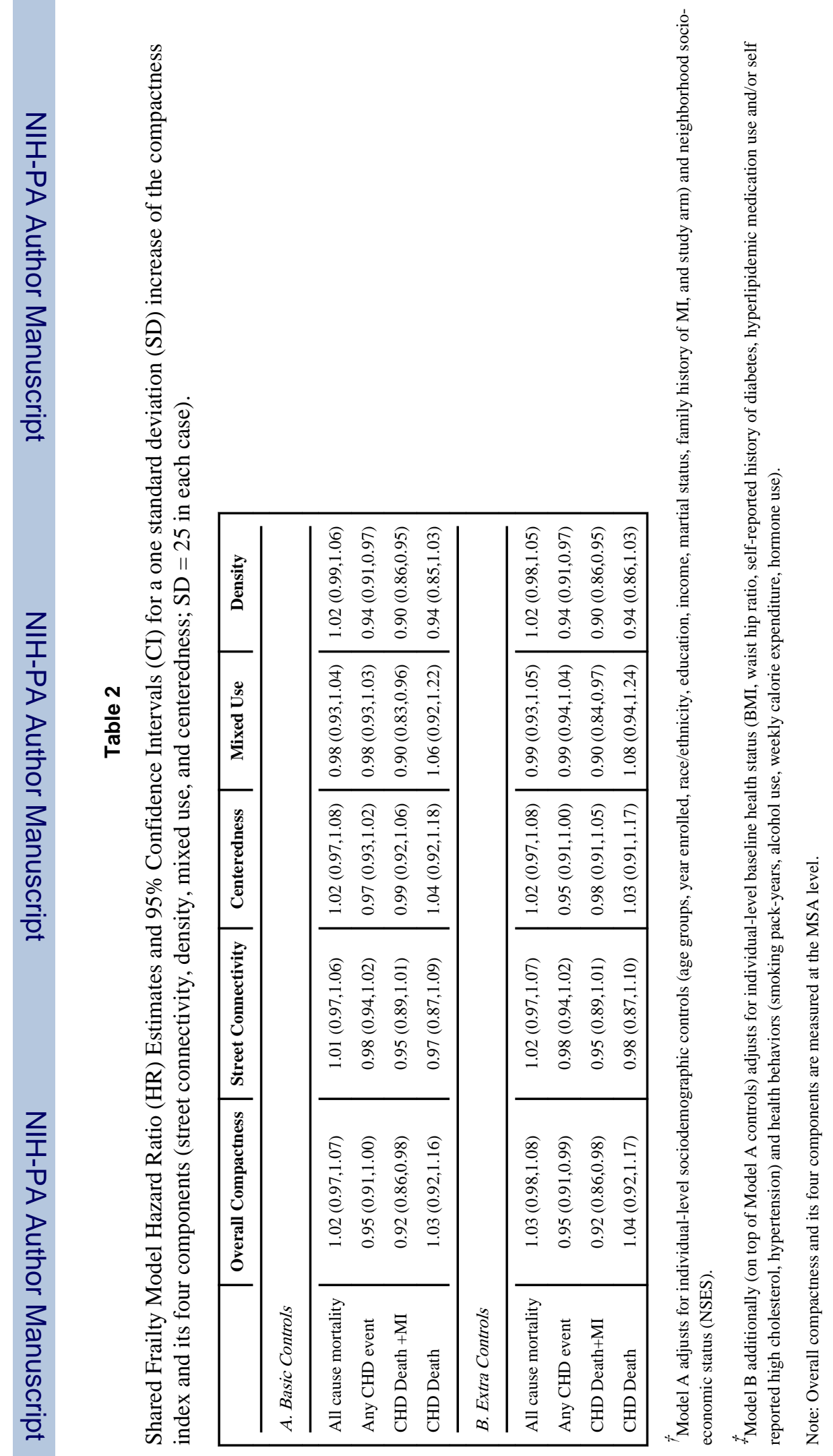

Health Place. Author manuscript; available in PMC 2014 March 01. 


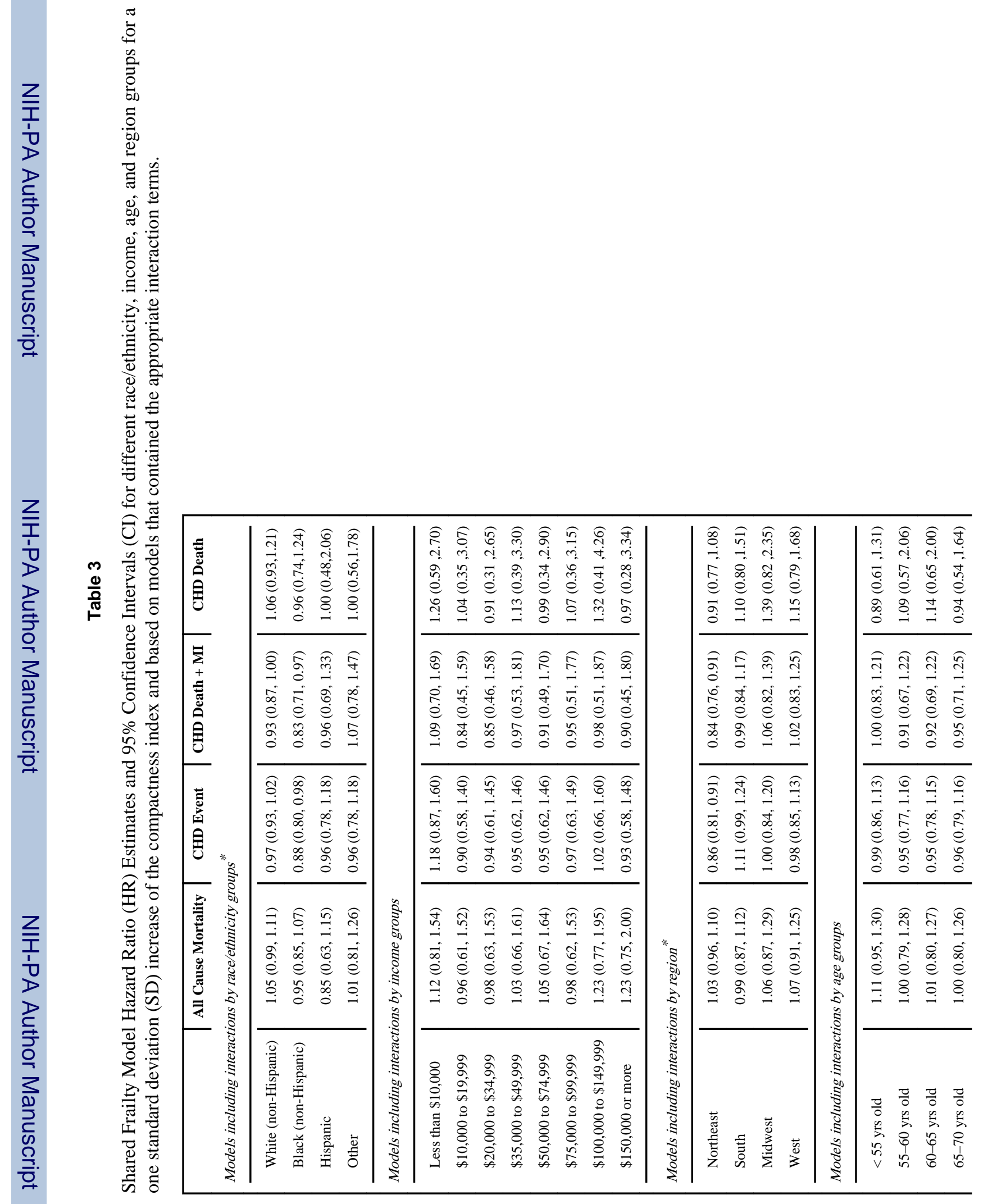




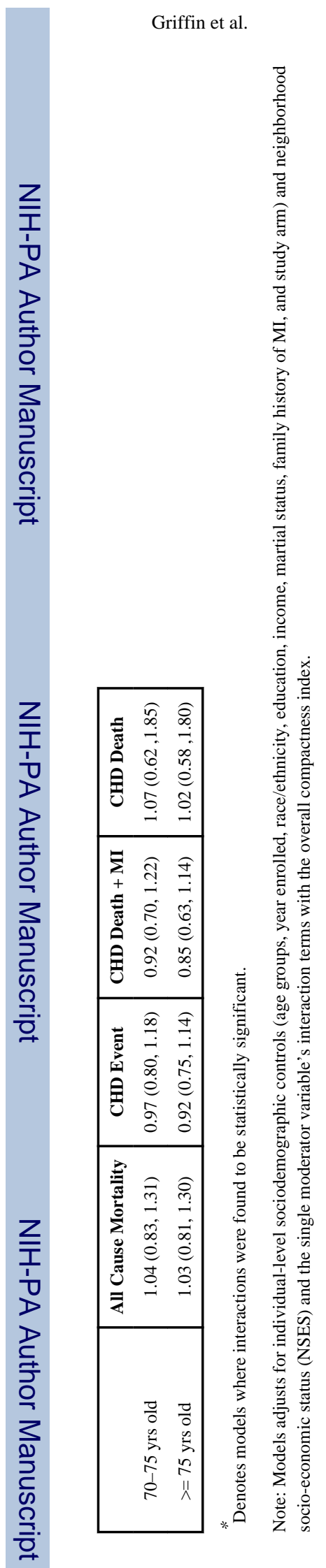

Page 23 
Appendix Table A.1

Comparison of Included and Excluded Women in the Analytic Sample

\begin{tabular}{|c|c|c|c|}
\hline & Included ( $\mathrm{N}=\mathbf{4 5 , 4 2 6 )}$ & Excluded (N=22,706) & T-test ${ }^{a}$ \\
\hline Age at baseline (in years) & $62.6(7.1)$ & $62.9(6.8)$ & -4.46 \\
\hline Experienced any CHD event & $6.6 \%$ & $7.4 \%$ & -3.82 \\
\hline \multicolumn{4}{|l|}{ Race } \\
\hline White, non-Hispanic & $78.4 \%$ & $87.6 \%$ & -31.49 \\
\hline Black, non-Hispanic & $11.3 \%$ & $8.1 \%$ & 13.83 \\
\hline Hispanic & $5.4 \%$ & $2.0 \%$ & 24.21 \\
\hline Other & $4.6 \%$ & $2.2 \%$ & 17.78 \\
\hline \multicolumn{4}{|l|}{ Education } \\
\hline$<$ High School & $5.6 \%$ & $5.5 \%$ & 0.92 \\
\hline High School Graduate & $27.3 \%$ & $32.6 \%$ & -14.09 \\
\hline Some College & $29.0 \%$ & $28.7 \%$ & 0.82 \\
\hline College Graduate & $37.4 \%$ & $32.7 \%$ & 12.20 \\
\hline \multicolumn{4}{|l|}{ Income } \\
\hline$<\$ 35,000$ & $39.6 \%$ & $43.4 \%$ & -9.45 \\
\hline$\$ 35,000-74,999$ & $38.4 \%$ & $37.5 \%$ & 2.39 \\
\hline$\$ 75,000$ and over & $16.0 \%$ & $13.7 \%$ & 7.77 \\
\hline \multicolumn{4}{|l|}{ Marital Status } \\
\hline Never married & $4.5 \%$ & $2.9 \%$ & 10.82 \\
\hline Divorced or Separated & $17.2 \%$ & $14.5 \%$ & 9.26 \\
\hline Widowed & $16.8 \%$ & $17.3 \%$ & -1.60 \\
\hline Married & $59.4 \%$ & $63.3 \%$ & -10.05 \\
\hline Marriage-like relationship & $1.6 \%$ & $1.6 \%$ & 0.19 \\
\hline
\end{tabular}

${ }^{a}$ The t-test compares the value for included women to the value for excluded women. 


\section{Appendix Table A.2}

Shared Frailty Model Hazard Ratio (HR) Estimates and 95\% Confidence Intervals (CI) for a one standard deviation (SD) increase of the compactness index and tract-level measures of log of population density, NSES, and walkability (alpha and gamma indices).

\begin{tabular}{|l|l|l|l|l|}
\hline & All Cause Mortality & Any CHD Event & CHD Death + MI & CHD Death \\
\hline \multicolumn{5}{|l|}{ Models including the alpha index } \\
\hline Overall Compactness & $1.02(0.97,1.08)$ & $0.94(0.90,0.98)$ & $0.91(0.85,0.98)$ & $1.02(0.90,1.16)$ \\
Alpha Index & $1.03(0.97,1.08)$ & $1.03(0.98,1.08)$ & $1.07(1.00,1.15)$ & $1.07(0.94,1.21)$ \\
NSES & $0.91(0.87,0.96)$ & $0.90(0.86,0.95)$ & $0.90(0.84,0.96)$ & $0.81(0.72,0.92)$ \\
Log of Pop. Density & $1.00(0.95,1.05)$ & $0.97(0.93,1.02)$ & $0.94(0.88,1.00)$ & $0.95(0.84,1.08)$ \\
\hline Models including the gamma index & $1.02(0.97,1.08)$ & $0.94(0.89,0.98)$ & $0.91(0.85,0.98)$ & $1.02(0.90,1.16)$ \\
\hline Overall Compactness & $1.03(0.98,1.09)$ & $1.03(0.98,1.08)$ & $1.08(1.00,1.15)$ & $1.08(0.95,1.22)$ \\
Gamma Index & $0.91(0.87,0.96)$ & $0.91(0.86,0.95)$ & $0.90(0.84,0.96)$ & $0.82(0.73,0.92)$ \\
NSES & $1.00(0.94,1.05)$ & $0.97(0.93,1.02)$ & $0.93(0.87,1.00)$ & $0.95(0.84,1.07)$ \\
Log of Pop. Density
\end{tabular}

All model A adjusts for individual-level sociodemographic controls (age groups, year enrolled, race/ethnicity, education, income, martial status, family history of MI, and study arm).

Note: Overall compactness is measured at the MSA level while population density and the alpha and gamma indices are measured at the censustract level.

Table Comment: This table illustrates the robustness of associations between overall compactness, CHD event, and CHD Death + MI when tractlevel measures of population density and walkability are added to the regression models. The significant findings for the neighborhood factors in relation to the CHD death + MI need to be taken with caution. In models where the neighborhood-level measures were added independently of one another, there was no evidence of significant associations between the walkability measures and CHD death + MI or population density and CHD death + MI. Further research that focuses on the neighborhood-level measures is needed to better understand the interplay between population density and the walkability indices for CHD Death + MI in these models and why it only occurs with this one outcome. 